\title{
Waste management barriers in developing country hospitals: Case study and AHP analysis
}

Waste Management \& Research

2018, Vol. 36(1) 48-58

(c) The Author(s) 2017

Reprints and permissions:

sagepub.co.uk/journalsPermissions.nav DOI: 10.1177/0734242X17739972

journals.sagepub.com/home/wmr

@SAGE

\author{
Diego V de Godoy Delmonico, Hugo H dos Santos, \\ Marco AP Pinheiro, Rosani de Castro and Regiane M de Souza
}

\begin{abstract}
Healthcare waste management is an essential field for both researchers and practitioners. Although there have been few studies using statistical methods for its evaluation, it has been the subject of several studies in different contexts. Furthermore, the known precarious practices for waste management in developing countries raise questions about its potential barriers. This study aims to investigate the barriers in healthcare waste management and their relevance. For this purpose, this paper analyses waste management practices in two Brazilian hospitals by using case study and the Analytic Hierarchy Process method. The barriers were organized into three categories - human factors, management, and infrastructure, and the main findings suggest that cost and employee awareness were the most significant barriers. These results highlight the main barriers to more sustainable waste management, and provide an empirical basis for multi-criteria evaluation of the literature.
\end{abstract}

\section{Keywords}

Sustainable operations, healthcare waste management, waste management, developing countries, multi-criteria decision making, analytic hierarchy process

Received 31 July 2017; accepted 8 October 2017 by Editor in Chief P Agamuthu.

\section{Introduction}

Although healthcare waste is merely a fraction of society's total waste (Abor and Bouwer, 2008), it is particularly harmful and creates biological and chemical risks for the environment and society, such as infections by contaminated materials, epidemic outbreaks, and chemical and radioactive poisoning. In this way, healthcare waste mismanagement is potentially dangerous to the population, especially in countries without proper legislation and disposal methods (Townend and Vallini, 2008).

In this context, solid-waste management (SWM) does not receive enough attention in developing countries (Da Silva et al., 2005), a fact that increases the importance of explaining the factors that might be hindering the development of proper healthcare waste management practices, granting relevance to the study of barriers, especially in the context of developing countries.

Although the value of waste management studies in developing countries is clear, only two studies that directly approach the Brazilian context were found. Da Silva et al. (2005) conducted studies on medical centers in the state of Rio Grande do Sul, while Moreira and Günther (2013) were focused on the city of São Paulo. The first study conducted surveys on waste management practices, while the second analysed the improvement of such practices after the implementation of a healthcare waste management plan, a document required by federal regulation.
The development of solid-waste management is a topic that has attracted attention from various sectors, and its improvement requires specialized knowledge. In addition, the lack of attention and the precariousness of these practices in the context of developing countries mean that studies on the barriers are highly relevant, and there is a gap in the literature from this perspective. This paper, therefore, seeks to contribute to the latest research by answering the following question: what are the most critical barriers to the development of hospital medical waste management practices in Brazil?

This study aims to describe the most important barriers related to the development of hospital medical waste management practices through analysis using the Analytic Hierarchy Process (AHP). First, the barriers to hospital medical waste

Department of Production Engineering, São Paulo State University (Unesp), Brazil

\section{Corresponding author:}

Diego Valério de Godoy Delmonico. Department of Production Engineering, São Paulo State University (Unesp), School of Engineering, Bauru (SP) - Brazil, Av. Eng. Edmundo C. Coube 14-01, DEP-FE. Bauru (SP) 17033360. Brazil.

Email: diegodelmonicolffclar.unesp.br 
management had to be identified from the literature and qualitative analysis.

The case studies were conducted in two hospitals in the city of Bauru, in the state of São Paulo, to map out the difficulties facing hospital medical waste management practices, through visits and meetings with the managers, and the application of AHP questionnaires.

The findings suggest that a lack of awareness and costs are the main barriers for hospital waste management, followed by a lack of management guidelines. The differences between the two cases are discussed by considering their managerial approach.

\section{Conceptual review}

Solid-waste management is related to sustainable operations management practices (Ferreira et al., 2012; Gunasekaran et al., 2014). Solid-waste management can be defined as operational strategies, tactics, techniques, and operational policies that support both the economic and environmental objectives as well as covering subtopics such as sustainable supply chains, eco-design, and sustainable procurement (Gunasekaran et al., 2014).

One problem within the study of healthcare waste management practices is that their concept and related themes, such as "medical waste" or "infectious waste" are still poorly defined and there is no universally accepted standard (Askarian et al. 2010; Rutala and Mayhall, 1992). This fact is a barrier to the application and comparison between models in existing contexts.

Several studies (e.g., Abd El-Salam, 2010; Bendjoudi et al., 2009) use the definitions provided by the World Health Organization. This definition propose a concept of healthcare waste as the waste generated by hospitals, research centers, and medical clinics in diagnosis, immunization, treatment, and associated research (Abd El-Salam, 2010; Ananth et al. 2010; Chartier et al., 2014). Although this definition is widely used, it is important to notice that not all waste generated by hospitals and health institutions is potentially infectious (Gupta and Boojh, 2006), and can even lose its infectious character after autoclaving (Windfeld and Brooks, 2015). Askarian et al. (2010) argued that medical waste is defined as solid or semi-solid waste generated by health services in the course of diagnosis and treatment of humans or animals.

Many studies on healthcare waste management are developed based on case studies in specific places. The cases include specific countries (e.g., Hanumantha Rao, 2009; Tsakona et al., 2007; Tudor et al., 2007), regional dimensions (e.g., Karamouz et al., 2007), countries of the same block (e.g., Woolridge et al., 2005), and several countries (Wilson et al., 2012). Furthermore, most studies on healthcare waste management concluded that there is a lack of research on interventions aimed at improving solid-waste management practices, and that these practices require a combination of bottom-up solutions such as training programs, and top-down solutions through aspects such as governance and administration (Harhay et al., 2009).
In general, few studies focus on comprehensively systemizing the latest research on medical waste management. Windfeld and Brooks (2015) conducted a review that focused on healthcare waste management practices, sorting them into collection and separation, transportation and disposal, presenting the regulatory practices of the US, Canada, the UK, the EU and developing countries.

Insa et al. (2010) conducted a critical review of the legal structure regarding solid-waste management in Spain. The authors presented the characteristics of the regulations in various Spanish regions, demonstrating the heterogeneity of standards in different locations. The authors noted that this plurality occurs due to the lack of national and international regulations.

Caniato et al.'s (2015) objectives were to identify key policies, practices, best practices, and challenges, analyzing the results based on the gross domestic product (GDP) of each region. The study found that a national strategy with proper policies is one of the key factors of a proper governance structure, and identified the need for training, guidelines, and the involvement of top management as a priority.

AHP was introduced by Thomas L. Saaty in 1980 and is currently considered to be one of the most used multiple criteria decision-making process techniques in the literature (Ho, 2008; Vaidya and Kumar, 2006). In decision making, the most important factors must be considered, and AHP organizes these factors into levels using a hierarchical structure that comprises the objective, criteria, sub-criteria, and alternatives involved in the decision-making process (Saaty, 1990). The technique gives decision makers a transformation of subjective judgments on objective measures. AHP has been widely used in several fields, such as engineering, food, business, ecology, and government (Sipahi and Timor, 2010).

AHP consists of a proper mathematical structure for studying and prioritizing barriers within various contexts. Shi et al. (2008) applied AHP in examining and prioritizing the main barriers to the adoption of clean production in small- and medium-size enterprises in China. Nagesha and Balachandra (2006) used the method in small-scale industries in India to prioritize the essential barriers that hinder improvements in energy efficiency. Vanany (2011) identified the main barriers to the adoption of radio frequency identification (RFID) in hospitals and other health service centers in Asian countries. For these and other studies found in the literature, the AHP technique becomes an appropriate tool for prioritizing barriers related to the implementation of healthcare waste management.

\section{Material and methods}

\section{Case studies}

The current situation was described regarding hospital SWM practices in two hospitals located in the city of Bauru. Barriers to waste management practices, barriers in the opinions of managers, and differences in the treatment of healthcare waste were mapped. Sampling was used considering the research objectives; 
waste regulations are generally established at a national level, suggesting that these local hospitals face similar challenges in waste management system implementation.

Considering the cautions and the method of systematization proposed by Voss et al. (2002) the purpose of the case studies was to map the key variables needed to understand the barriers to hospital medical waste management and to support a deeper understanding of their nature. From this perspective, interviews, direct observation, and analysis of the institutions' waste plans were conducted. Analysis of the case studies, therefore, focused on three factors: the possibility of presenting the institutional situation at the studied organizations, the supply of bases for the development of the multi-criteria research instrument, and the possibility of further discussion of the results obtained via multicriteria analysis.

\section{Analytic hierarchy process}

Variables, collection and analysis. The research variables identified in the literature were divided into three broad categories: infrastructure, human factors, and management. Table 1 shows the barriers described in the literature and characterized by the experts for each of these categories, with a brief description and the sources used.

Data collection in the AHP technique involves applying paired questionnaires, measuring the importance between two elements in relation to another element from a higher level of the hierarchy. This was carried out with those directly responsible for waste management at the two hospitals.

The AHP questionnaires were analysed using SuperDecisions software (Creative Decisions Foundation, Pittsburgh, Pennsylvania, USA), which was developed to support decision makers and calculates the priorities for each decision matrix present in the analysis, identifying the consistency of responses and ranking the proposed alternatives for the decision. Based on the procedures conducted in the software, it was possible to determine a weighting for the barriers identified and list those with the most influence on the management and maintenance of healthcare waste.

Structuring and instrument. The study was prepared using the steps defined by Vaidya and Kumar (2006) as well as the procedures established by Govindan et al. (2014), which led to the problem being structured in the following steps.

1. After a brief description of the literature and presentation of the barriers to implementation and maintenance of healthcare waste management, a consultation was held with experts from the two hospitals to discuss the topic. Using the advance information on the key issues provided by the experts and the literature review, the main barrier categories and specific barriers for each category were established.

2. After obtaining all of the decision elements, the hierarchical decision analysis structure was developed (Figure 1) with four levels:
Level 1: General objective;

Level 2: Barrier categories or barrier clusters;

Level 3: Specific barriers according to each category;

Level 4: Identification of the main barriers to the implementation of a healthcare waste management system.

3. The questionnaire developed from the AHP method was developed and sent to the experts at the two participating hospitals, to make the paired comparisons. The judgments were made according to the scale of reference between two elements, developed by Saaty, 1990, presented in Table 2.

4. Identification of the consistency of the responses provided by decision makers, where the consistency ratio should not exceed $10 \%$, as established by the method (Saaty, 1990). Two steps were used to make the calculation. First, the eigenvector or the relative weightings and $\lambda_{\max }$ are calculated for each matrix of order $n$ (equation (1)), and then the consistency (equation (2)) index was computed for each matrix of order $n$

$$
\begin{gathered}
C I=\frac{\left(\lambda_{\max }-n\right)}{n-1} \\
C R=\frac{C I}{R I}
\end{gathered}
$$

The value of RI consists of a random index according to the number of criteria that are used in the analysis (Saaty, 1990), as shown in Table 3.

\section{Case study results and analysis discussion}

\section{Case studies}

The two hospitals are relatively equivalent in their operation, claiming to have a wide range of services. In both cases care is provided in more than 40 specialities ranging from small therapies to clinical oncology. Their respective infrastructures have a surgical center, outpatient surgical center, ambulatory care, intensive care units, and diagnostic and therapeutic support service, without a formal specialization of care and services.

The hospitals perform the same types of care, with some minor exceptions due to differences in the coverage of the public health system, such as restrictions on plastic surgery within the public health system. In any case, as is common in the Brazilian health system, the hospitals try to act comprehensively and hardly specialize, and agree on service and protocol systems to avoid the problems of demand and infrastructure that affect care.

In respect to waste separation, Brazil has very detailed national regulations and a system of technical standards that outline the best concepts and methods for solid-waste management as proposed by organizations such as the National Council 


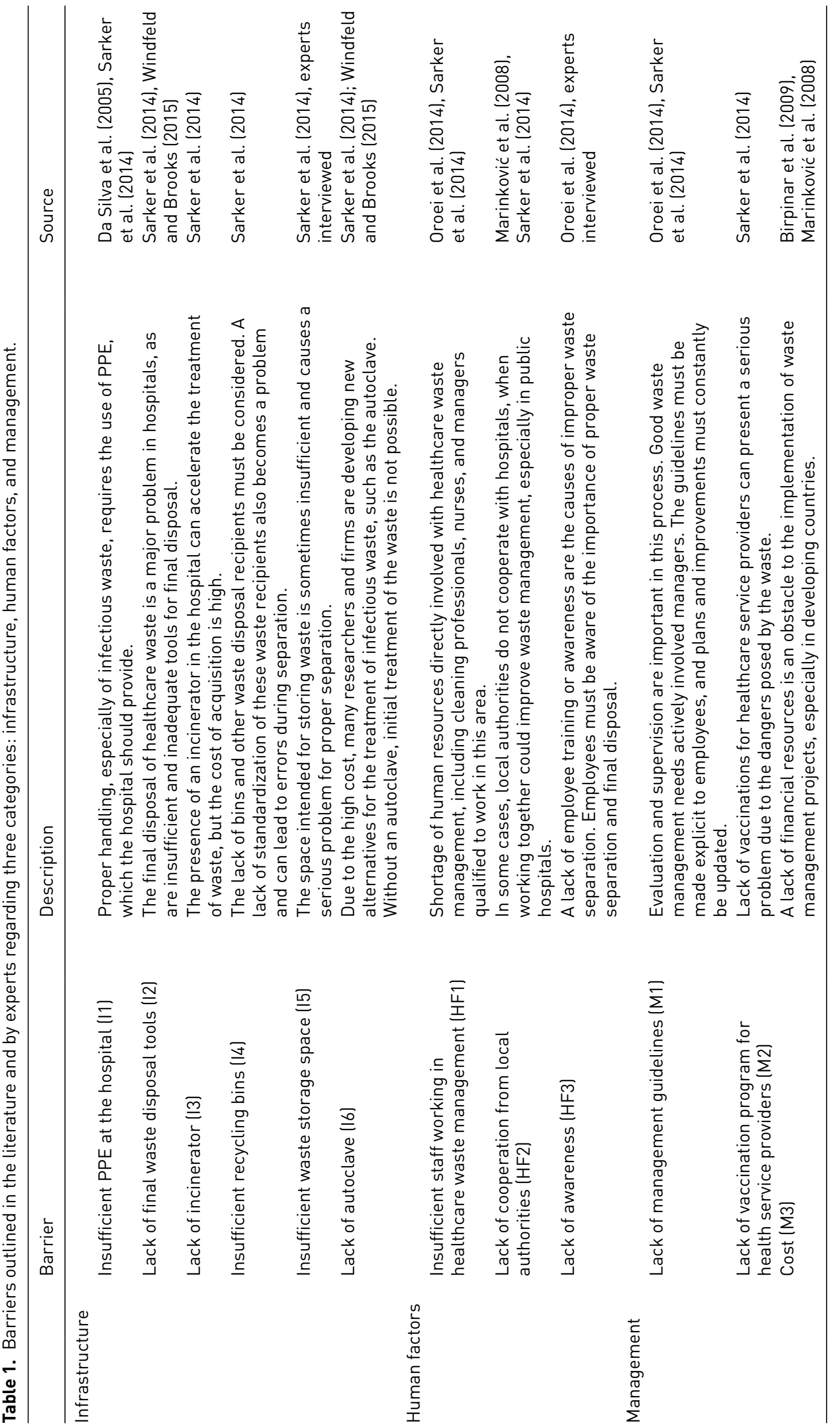




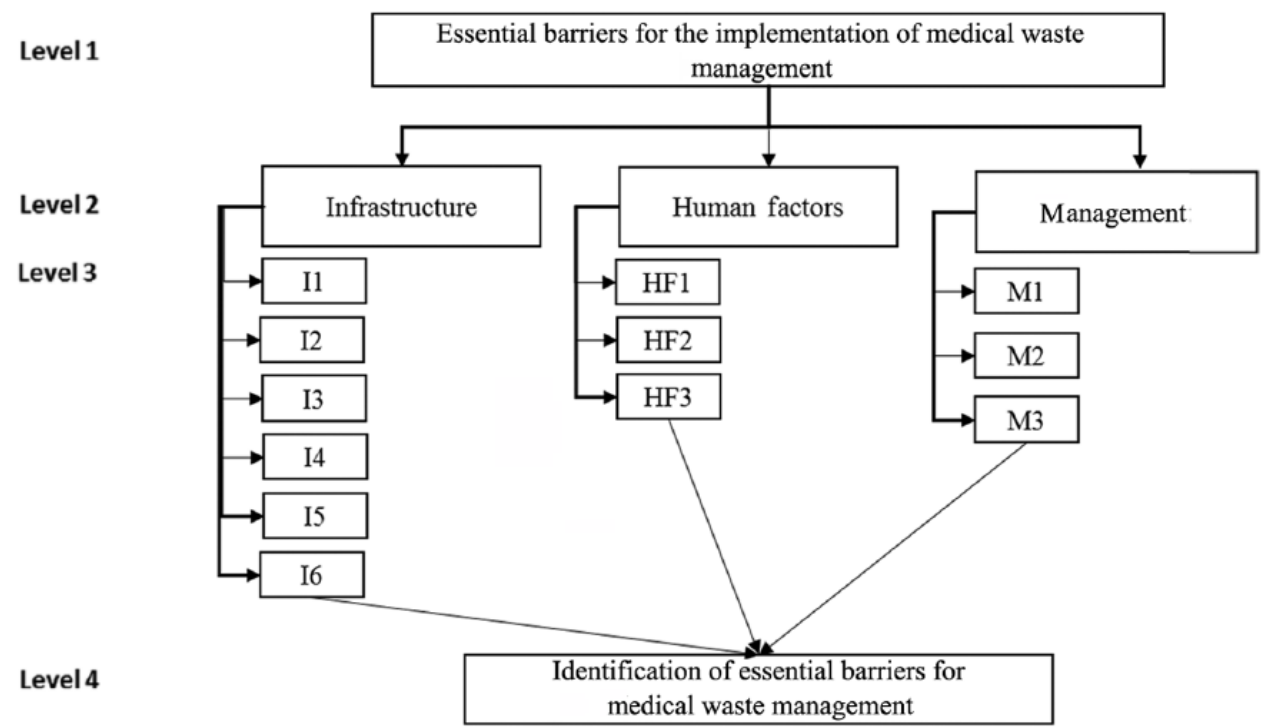

Figure 1. AHP structure for identifying barriers to the implementation of a healthcare waste management system.

Table 2. Scale of reference between two elements, developed by Saaty (1990).

\begin{tabular}{lll}
\hline Importance level & Definition & Explanation \\
\hline 1 & $\begin{array}{l}\text { Equal importance } \\
\text { One slightly more important } \\
\text { than the other }\end{array}$ & $\begin{array}{l}\text { Two activities contribute equally to the objective } \\
\text { Experience and judgment slightly favor one activity over another }\end{array}$ \\
5 & $\begin{array}{l}\text { Strong or essential importance } \\
\text { Very strong importance }\end{array}$ & $\begin{array}{l}\text { Experience and judgment strongly favor one activity over another } \\
\text { One activity is favored very strongly over another and its } \\
\text { dominance is demonstrated in practice. }\end{array}$ \\
9 & Absolute importance & $\begin{array}{l}\text { Evidence favors one activity over another with the highest degree } \\
\text { of certainty }\end{array}$ \\
$2,4,6,8$ & Intermediate values between & Compromise between two definitions \\
Reciprocity & If activity $i$ is assigned one of the above non-zero numbers when compared to activity $j$, then $j$ has a \\
& reciprocal value when compared to $i$
\end{tabular}

Table 3. Random index (RI) values according to Saaty (1990).

\begin{tabular}{|c|c|c|c|c|c|c|c|c|c|c|}
\hline$n$ & 1 & 2 & 3 & 4 & 5 & 6 & 7 & 8 & 9 & 10 \\
\hline RI & 0 & 0 & 0.52 & 0.89 & 1.11 & 1.25 & 1.35 & 1.4 & 1.45 & 1.49 \\
\hline
\end{tabular}

of the Environment (CONAMA) and the Brazilian Association of Technical Standards (ABNT). According to Brazilian regulations, healthcare waste separation is divided into five groups, depending on the type of danger posed by the waste: A, contaminant; $\mathrm{B}$, chemical; $\mathrm{C}$, radioactive; D, common; E, sharp objects (ABNT, 2013). Each has its specific separation and disposal issues, see Alves et al. (2014).

Table 4 shows the amount of waste per type in each hospital. It is important to notice that waste type $\mathrm{E}$ (sharps and blades) is treated as a contaminant for measurement purposes, with a similar risk of contamination and destination, with different collection methods and containers.

Hospital 1. Hospital 1 is owned by a medical cooperative and is part of a complex that includes several hospitals across the country and numerous areas of the health service. It is a point of reference for other units belonging to the complex because of its design, which is considered bold, with plenty of space for patients and support, as well as for the excellent care it provides. It currently has 230 beds in operation, 1000 permanent employees, and a medical staff consisting of more than 690 doctors; it covers an area of $96,700 \mathrm{~m}^{2}$, with $20,111.48 \mathrm{~m}^{2}$ of buildings and construction projects in progress; average monthly attendance is 1500 admissions and 1000 surgeries. The average number of adult and child emergency care consultations exceeds 9500 per month.

A multidisciplinary committee of professionals and workers oversees preparation of the healthcare waste management plan for Hospital 1. These committee meetings are held monthly, but extraordinary meetings can be held for special cases. The plan has a two-year cycle for its revision. 
Table 4. Average waste generated by type.

\begin{tabular}{lll}
\hline & \multicolumn{2}{l}{$\begin{array}{l}\text { Waste generated } \\
\text { [kg/day] }\end{array}$} \\
\cline { 2 - 3 } & Hospital 1 & Hospital 2 \\
\hline Contaminant (A) and & 403 & 416 \\
sharps and blades (E) & & \\
Chemical (B) & 23 & 10 \\
Common (D) & 319 & 355 \\
Paper & 48 & 54 \\
Cardboard & 38 & 42 \\
Plastic & 44 & 49 \\
Metal & 0.4 & 0.4 \\
Glass & 0.2 & 0.3 \\
Total & 875 & 927 \\
\hline
\end{tabular}

Weighting of waste type $\mathrm{D}$ (radioactive) is negligible.

Hospital 2. Hospital 2 is a public state hospital, run by a private foundation, and is part of a relatively new management model adopted by the government, which hires social organizations to manage public hospitals to ensure greater management flexibility.

This model establishes the contract between social health organizations (OSS) and the state and, in this case, responsibility for the management of the institution and the fulfillment of targets related to production, care, and quality, stipulated by the State Health Department, to be borne by the contracted foundation, with the government responsible for financial maintenance of the hospital. Hospital 2 attends to the public through a universal public health system and has 14 clinics, 16 support rooms, and capacity for 318 beds. Hospital 2 currently hold an average of 10,000 medical consultations per month, plus 600 surgeries, 26,000 examinations, and 900 admissions.

Preparation of the healthcare management plan is the sole responsibility of the Specialist Occupational Health and Safety Engineering Service (SESMET), with meetings scheduled only when a new waste type is identified. The vast majority of operations relating to waste from Hospital 2 are the responsibility of a third party, which is also responsible for training hospital employees in waste separation and handling.

Table 5 provides a summary of the general information regarding the hospitals involved in the study.

\section{Results and discussion}

In accordance with the method used in the evaluation, a paired comparison was conducted between the problem objective (Level 1) and the barrier categories identified (Level 2). This comparison resulted in relative weighting for each category. This procedure was performed for both of the hospitals studied.

As can be seen in Table 6, each barrier category had the same importance for the experts at Hospital 1, with no differences between the categories infrastructure, human factors, and management.
In contrast, for the experts at Hospital 2, human factors had a greater weighting in relation to the other categories infrastructure and management (Table 7). The overall weightings calculated at the end of the AHP methodology were completely influenced by the greater importance given to human factors. As the levels are multiplied to obtain the final priorities, the greater the weighting of the human factors criterion, the heavier will be its specific barriers in the final results, from a broader perspective.

The rankings of specific barriers for Hospital 1 (Table 8) and Hospital 2 (Table 9) were determined by the overall weighting provided by the AHP approach, obtained by multiplying the relative weightings for each category by the relative weighting of each specific variable. The consistency analyses for the decision matrices were less than $10 \%$, which is recommended by the method in accordance with the application of equations (1) and (2).

The three top barriers identified for Hospital 1 were the cost (M3), the lack of employee awareness regarding waste separation (HF3), and the lack of an autoclave (I6).

For Hospital 2, the three most important barriers were a lack of employee awareness regarding waste separation (HF3), a lack of management guidelines (M1), and insufficient staff working in healthcare waste management (HF1). For Hospital 2, the greater weighting given to human factors resulted in two of its three main barriers emerging in the results.

The different weighting of the main criteria at Hospital 2 enables a sensitivity analysis of the results. The sensitivity analysis is the final step of the AHP methodology, serving as a basis for stability testing of the final ranking of the decisionmaking priorities. The final weightings for each alternative rely heavily on the main analysis criteria. Thus, some alternative scenarios can be created due to the increased or decreased weighting of criteria. This change in weighting directly impacts on decision-making results (Chang et al., 2007; Ishizaka and Labib, 2011).

The results from Hospital 1 did not enable a sensitivity analysis since all of the criteria had the same weight. At Hospital 2, because the human factors criteria were given greater weighting in the analysis, a sensitivity analysis was performed to test the final ranking of the barriers, varying the weighting of the human factors from 0.1 to 0.9 . When the human factors weighting was 0.1 , the lack of management guidelines barrier (M1) became the main barrier, and the lack of cooperation from local authorities barrier (HF2) became the lowest priority. All changes to the final ranking of the barriers in all scenarios are presented in Table 10 and graphically in Figure 2.

Up to a weighting of 0.2 , the lack of management guidelines barrier (M1) is the priority, but based on the weighting of 0.3 inferred for human factors, the lack of awareness barrier (HF3) appears to be the largest concern for managers. These results demonstrate the impact that human factors have on waste maintenance and management at Hospital 2. Immediate removal of the barriers related to human factors could favor a considerable improvement of the waste management conditions at Hospital 2. 
Table 5. Summary of general information regarding the hospitals involved in the study.

\begin{tabular}{lll}
\hline & Hospital 1 & Hospital 2 \\
\hline Total beds & 230 & 318 \\
Patients/day & 306 & 322 \\
Solid-waste management plan & Yes, responsibility of the committee & Yes, responsibility of SESMET \\
Regularity of meetings & Monthly & Only in special cases \\
Review of plan & In theory, the plan is reviewed every two & Only in special cases \\
& years & \\
Waste identification and separation & According to Anvisa RDC No. 306 & According to Anvisa RDC No. 306 \\
Internal collection and & Collected by employees and transported & Collected by cleaning company and \\
transportation & in specific carts & transported in specific carts \\
Temporary waste storage & Purges spread across the whole hospital & Purges spread across the whole hospital \\
Storage & Specific sheds for each type of waste & Specific sheds for each type of waste \\
Autoclave & Has an autoclave & Not included \\
External collection and transportation & Third party & Third party \\
Final disposal & Sanitary landfills & Sanitary landfills \\
Training & Regular training & Regular training \\
Sustainability practices & Water treatment & Recycling of cardboard, plastics, and \\
Average waste generated per & 26,257 kg & metals \\
month & & 27,820 kg
\end{tabular}

Table 6. AHP weightings for barrier categories at Hospital 1.

\begin{tabular}{lllll}
\hline & Infrastructure & Human factors & Management & Weighting \\
\hline Infrastructure & 1 & 1 & 1 & 0.3333 \\
Human factors & 1 & 1 & 1 & 0.3333 \\
Management & 1 & 1 & 1 & 0.3333 \\
\hline
\end{tabular}

Table 7. AHP weightings for barrier categories at Hospital 2.

\begin{tabular}{lllll}
\hline & Infrastructure & Human factors & Management & Weighting \\
\hline Infrastructure & 1 & $1 / 3$ & 1 & 0.2000 \\
Human factors & 3 & 1 & 3 & 0.6000 \\
Management & 1 & $1 / 3$ & 1 & 0.2000 \\
\hline
\end{tabular}

Table 8. Local and overall weightings for all barrier categories and specific barriers at Hospital 1.

\begin{tabular}{lllll}
\hline Barrier category & Weighting using AHP & Barrier & Weighting using AHP & Overall weighting using AHP \\
\hline Infrastructure & 0.3333 & 11 & 0.0988 & 0.0329 \\
& & 12 & 0.1172 & 0.0390 \\
& 13 & 0.0188 & 0.0063 \\
& & 0.1172 & 0.0390 \\
Human factors & \multirow{2}{*}{0.3333} & $\mathrm{I}$ & 0.2654 & 0.0884 \\
& & $\mathrm{I}$ & 0.3827 & 0.1276 \\
Management & $\mathrm{HF1}$ & 0.0879 & 0.0293 \\
& $\mathrm{HF2}$ & 0.2426 & 0.0809 \\
& $\mathrm{HF3}$ & 0.6694 & 0.2231 \\
& $\mathrm{M} 1$ & 0.1429 & 0.0476 \\
\end{tabular}

Analysis of barrier importance results. For proper maintenance of healthcare waste management, hospital infrastructure is a critical category for ensuring that all procedures up to the final disposal of waste are performed. For the experts at Hospital 1, the 
Table 9. Local and overall weightings for all barrier categories and specific barriers at Hospital 2.

\begin{tabular}{|c|c|c|c|c|}
\hline Barrier category & Weighting using AHP & Barriers & Weighting using AHP & Overall weighting using AHP \\
\hline \multirow[t]{6}{*}{ Infrastructure } & \multirow[t]{6}{*}{0.2000} & 11 & 0.4736 & 0.0947 \\
\hline & & 12 & 0.2606 & 0.0521 \\
\hline & & 13 & 0.0228 & 0.0046 \\
\hline & & 14 & 0.0492 & 0.0098 \\
\hline & & 15 & 0.1656 & 0.0331 \\
\hline & & 16 & 0.0282 & 0.0056 \\
\hline \multirow[t]{3}{*}{ Human factors } & \multirow[t]{3}{*}{0.6000} & HF1 & 0,1829 & 0.1097 \\
\hline & & HF2 & 0.0509 & 0.0306 \\
\hline & & HF3 & 0.7662 & 0.4597 \\
\hline \multirow[t]{3}{*}{ Management } & \multirow[t]{3}{*}{0.2000} & M1 & 0.6548 & 0.1310 \\
\hline & & M2 & 0.0953 & 0.0191 \\
\hline & & M3 & 0.2499 & 0.0500 \\
\hline
\end{tabular}

Table 10. Values of the barrier categories after variation of human factor criteria weightings during sensitivity analysis.

\begin{tabular}{|c|c|c|c|c|c|c|c|c|c|c|c|c|}
\hline & \multicolumn{12}{|c|}{ Values of barrier categories during sensitivity analysis } \\
\hline & 11 & 12 & 13 & 14 & 15 & 16 & HF1 & HF2 & HF3 & M1 & M2 & M3 \\
\hline 0.1 & 0.213 & 0.117 & 0.010 & 0.022 & 0.074 & 0.013 & 0.018 & 0.005 & 0.077 & 0.295 & 0.043 & 0.113 \\
\hline 0.2 & 0.189 & 0.104 & 0.009 & 0.020 & 0.066 & 0.011 & 0.037 & 0.010 & 0.153 & 0.262 & 0.038 & 0.100 \\
\hline 0.3 & 0.166 & 0.091 & 0.008 & 0.017 & 0.058 & 0.010 & 0.055 & 0.015 & 0.230 & 0.229 & 0.033 & 0.088 \\
\hline 0.4 & 0.142 & 0.078 & 0.007 & 0.015 & 0.050 & 0.008 & 0.073 & 0.020 & 0.306 & 0.197 & 0.029 & 0.075 \\
\hline 0.5 & 0.118 & 0.065 & 0.006 & 0.012 & 0.041 & 0.007 & 0.091 & 0.026 & 0.383 & 0.164 & 0.024 & 0.063 \\
\hline 0.6 & 0.095 & 0.052 & 0.005 & 0.010 & 0.033 & 0.006 & 0.110 & 0.031 & 0.460 & 0.131 & 0.019 & 0.050 \\
\hline 0.7 & 0.071 & 0.039 & 0.003 & 0.007 & 0.025 & 0.004 & 0.128 & 0.036 & 0.536 & 0.098 & 0.014 & 0.038 \\
\hline 0.8 & 0.047 & 0.026 & 0.002 & 0.005 & 0.017 & 0.003 & 0.146 & 0.041 & 0.613 & 0.066 & 0.010 & 0.025 \\
\hline 0.9 & 0.024 & 0.013 & 0.001 & 0.002 & 0.008 & 0.001 & 0.165 & 0.046 & 0.690 & 0.033 & 0.005 & 0.013 \\
\hline
\end{tabular}

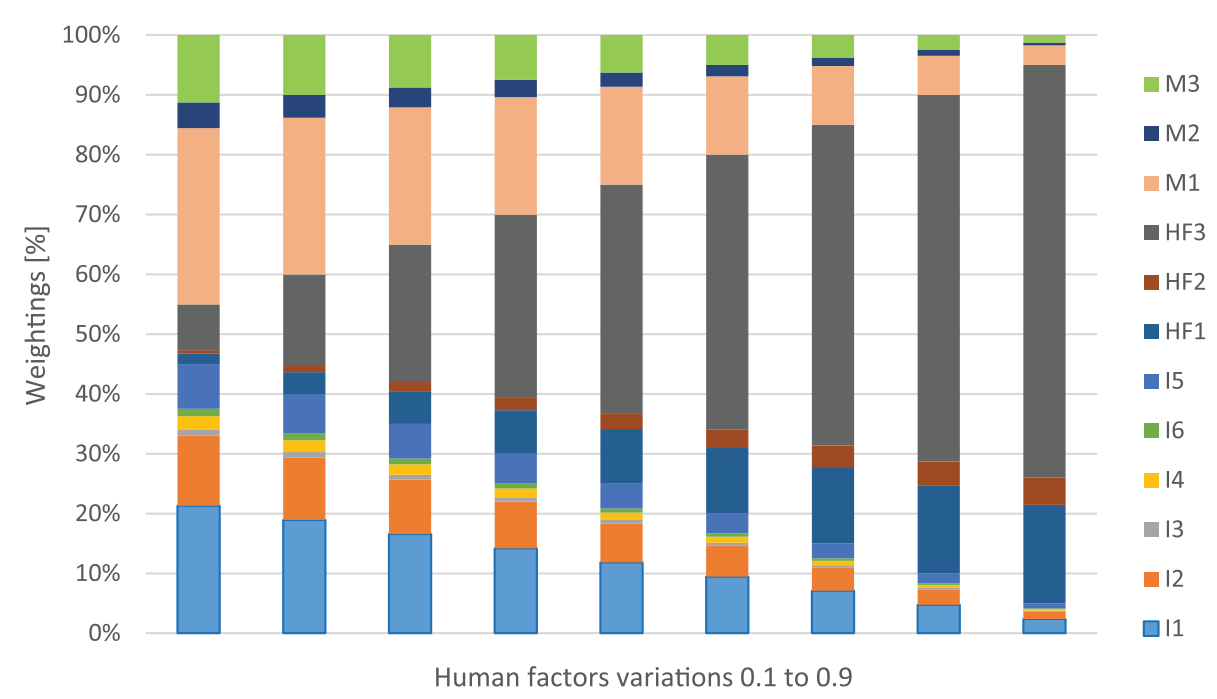

Figure 2. Ranking of specific barriers when the weightings for human factors vary during sensitivity analysis.

most significant barriers related to infrastructure were the lack of an autoclave (I6) and insufficient waste storage space (I5). Table 10 demonstrates the importance of specific barriers from the analysis, ordering them by barrier category.

The autoclave is characterized as an initial solid-waste treatment process that eliminates some pathogenic agents, but the appearance of the waste after treatment generates inquiries into whether the waste is fully suitable for final disposal. This causes many organizations to treat waste by incineration as well as an autoclave, thus leading to repeat treatment (Windfeld and Brooks, 2015). This repetition is a waste of energy since the initial treatment by autoclave can be replaced entirely by incineration. 
Table 11. Barrier importance position at the studied hospitals, in three categories: infrastructure, human factors, and management.

\begin{tabular}{llll}
\hline Category & & Hospital 1 & Hospital 2 \\
\hline Infrastructure & & 5 & 1 \\
& I1 - Insufficient PPE at the hospital & 3 & 2 \\
& I2 - Lack of final waste disposal tools & 6 & 6 \\
& I3 - Lack of incinerator & 4 & 4 \\
& I - Insufficient recycling bins & 2 & 3 \\
I5 - Insufficient waste storage space & 1 & 5 \\
Human factors & I6 - Lack of autoclave & 3 & 2 \\
& HF1 - Insufficient staff working in healthcare waste management & 2 & 3 \\
Management & HF2 - Lack of cooperation from local authorities & 1 & 1 \\
& HF3 - Lack of employee awareness regarding waste separation & 2 & 2 \\
& M1 - Lack of management guidelines & 3 & 1 \\
\hline
\end{tabular}

Insufficient waste storage space (I5) is a result of the amount of infectious waste generated in Hospital 1. The increased demand for health services generates substantial volumes of waste, and the storage structure must be able to accommodate the increased waste that results. According to the experts at Hospital 1 , it is essential to increase waste storage capacity, especially for infectious waste, which explains why this barrier is identified as the fourth most important of all the barriers identified by the AHP method.

For Hospital 2, the most critical infrastructure barrier identified was insufficient personal protective equipment (PPE) (I1). Waste disposal requires appropriate protective equipment for employees and training in proper waste handling. Other studies have also identified the lack of PPE as one of the main barriers to the implementation of hospital waste management (Da Silva et al., 2005; Sarker et al., 2014). This point makes it possible to check how concerned the experts at Hospital 2 are with improvements in occupational safety, and how the hospital management needs to act to contain this type of barrier, working more actively on this issue. Note that for Hospital 2, the infrastructure barriers were not determinant, with the lack of autoclave (I6) and lack of incinerator (I3) showing less importance than other barriers. In this matter, the hospital outsources most of its waste services, a crucial point in identifying the reactive way in which the management approaches the subject, which can explain the lower perceived importance of disposal infrastructures.

Human factors are relevant categories for healthcare waste management, and the AHP analysis showed how these barriers are recurring issues at both hospitals. The lack of employee awareness regarding waste separation (HF3) was the most significant barrier for Hospital 1 and Hospital 2, considering all the barriers identified during the analysis. Incorrect waste separation can cause various problems for hospitals, including environmental problems and economic problems. For example, infectious waste disposed of as general waste creates a large-scale environmental impact. Another example is of non-infectious waste being disposed of as infectious waste, which increases the cost of final waste disposal.

Regarding to the abovementioned barrier, lack of employee awareness regarding waste separation (HF3), the respondents from both hospitals declared that training programs are carried out to emphasize the importance and the rules for the proper disposal of materials. Thus, what seems to be a determinant is the lack of perception about the dimension and importance of individual actions in waste separation for adequate solid-waste management. Consequently, although the obvious mitigation for this barrier is proper training, the lack of training or poor quality of the given training was not necessarily seen as an issue.

Incorrect disposal of general waste as infectious waste causes waste management efficiency loss and escapes the control of senior management. In this regard, it was a highly weighted barrier when compared to others. The limited knowledge of employees and a lack of sensitivity and training were similar to other studies' results (Da Silva, 2005; Oroei et al., 2014; Sarker et al., 2014). The broad participation of hospital management is important for solving this problem, which requires regular training, the active involvement of top management, the correct placement of permanent and temporary waste storage, and proper checks over final disposal.

It is also worth mentioning insufficient staff working in healthcare waste management (HF1), which is the second largest barrier at Hospital 2. One of the reasons for the high weighting of this factor relates to the staff responsible for waste management. Unlike Hospital 1, which has a committee that reviews all wasterelated issues, at Hospital 2 the Specialist Occupational Health and Safety Engineering Service (SESMET) team are fully responsible for waste management. The development of a dedicated team for the hospital's waste management plan control is a viable option that could provide benefits when addressing the human factors barriers identified in this study.

As can be seen in Table 11, cost (M3) is the most significant barrier from the management category for both Hospital 1 and Hospital 2, considering all the barriers identified in the analysis. 
This characteristic reinforces the idea that cost is one of the major constraints in waste management, especially in developing countries (Birpinar et al., 2009; Marinković et al., 2008).

Lack of management guidelines is the second most significant barrier at both hospitals. The insufficient measures imposed by the management of the hospitals is related to the reactive method adopted by their managers in solving problems, which can be seen by the way that Hospital 2 deals with waste management, where the entire waste management process is the sole responsibility of SESMET, with no multidisciplinary team responsible for the area. Poor waste management demonstrates insufficient planning, a lack of organizational resources and ineffective monitoring and evaluation (Oroei et al., 2014). Management deficiencies can be explained by a lack of knowledge regarding the risks that healthcare waste can cause in the community (Da Silva et al., 2005).

According to the World Health Organization guidelines, successful waste management requires regular and effective training, as well as the construction of an information system (Oroei et al., 2014).

\section{Conclusions}

This research identified the strategic visions regarding healthcare waste management at the hospitals studied, one focused on longterm planning and implementation of waste management plans, and the other focused on responding to specific and unforeseen events.

The final weightings of the barriers identified offer a guide as to where the efforts of the hospitals should be directed in an aim to make better decisions regarding healthcare waste. In this sense, this study contributes to the literature by identifying the most significant barriers that prevent or hinder more sustainable healthcare waste management, prioritizing the barriers in categories related to infrastructure, human factors, and management in response to the different strategic visions implemented by the hospitals. The results contribute to allowing the hospitals to make decisions analytically and more objectively, reducing or seeking to address the most determinant barriers regarding waste management practices.

Cost, employee awareness, and lack of autoclaves stand out as the most significant barriers in relation to the analysis of management at Hospital 1. For Hospital 2, the main barriers were employee awareness, lack of management guidelines, and insufficient staff working in waste management. These results act as tools that seek to help hospital managers to combat the issues in healthcare waste management.

This research approaches healthcare waste management, emphasizing its variables in a wider perspective. In this sense, major barriers such as handling contaminated sharps (blades and needles) and the risk of contamination are treated as personnel training and infrastructure issues. Additionally, the recognition of barriers in the research was limited to the interviewees' declarations and a literature review. In this sense, it allows prevention and contamination issues to be treated as transversal themes underneath the barriers that are listed, or even merely seen to be an effect.

It is important to emphasize that this research sought to obtain knowledge about barriers to hospital waste management. The empirical results of this study should be understood within their methodological boundaries. Local case studies cannot be generalized, however, the value of these studies lies in their capability to raise practice issues of practice and to enable new directions for future research. Nevertheless, narrow observations are still largely used to approach healthcare waste management research, as presented in the literature review section.

\section{Declaration of conflicting interests}

The author(s) declared no potential conflicts of interest with respect to the research, authorship, and/or publication of this article.

\section{Funding}

The author(s) disclosed receipt of the following financial support for the research, authorship, and/or publication of this article: this research was indirectly supported by Coordination of Improvement of Higher Level Personnel (CAPES) and São Paulo State University (UNESP).

\section{References}

Abd El-Salam MM (2010) Hospital waste management in El-Beheira Governorate, Egypt. Journal of Environmental Management 91: 618629.

Abor PA and Bouwer A (2008) Medical waste management practices in a Southern African hospital. International Journal of Health Care Quality Assurance 21: 356-364.

Alves SB, Souza AC, Tipple AF, et al. (2014) The reality of waste management in primary health care units in Brazil. Waste Management \& Research 32: 40-47.

Ananth AP, Prashanthini V and Visvanathan C (2010) Healthcare waste management in Asia. Waste Management 30: 154-61.

Anvisa (2004) Resolução $n^{\circ} 306$ de 7 de dezembro de 2004. Availiable at: http://portal.anvisa.gov.br/documents/33880/2568070/res0306 07_12_2004.pdf/95eac678-d441-4033-a5ab-f0276d56aaa6

Askarian $\bar{M}$, Heidarpoor P and Assadian O (2010). A total quality management approach to healthcare waste management in Namazi Hospital, Iran. Waste Management 30: 2321-2326.

Bendjoudi Z, Taleb F, Abdelmalek F, et al. (2009) Healthcare waste management in Algeria and Mostaganem department. Waste Management 29: 1383-1387.

Birpinar ME, Bilgili MS and Erdoğan T (2009) Medical waste management in Turkey: A case study of Istanbul. Waste Management 29: 445-448.

Brazilian Association of Technical Standards [ABNT] (2013) NBR 12809: Resíduos de serviços de saúde: gerenciamento de resíduos de serviços de saúde intraestabelecimento. Rio de Janeiro: ABNT.

Caniato M, Tudor T and Vaccari M (2015) International governance structures for health-care waste management: A systematic review of scientific literature. Journal of Environmental Management 153: 93-107.

Chang CW, Wu CR, Lin CT, et al. (2007) An application of AHP and sensitivity analysis for selecting the best slicing machine. Computers \& Industrial Engineering 52: 296-307.

Chartier Y, Emmanuel J, Pieper U, et al. (eds) (2014) Safe Management of Wastes from Health-Care Activities, 2nd ed. Geneva: World Health Organization.

Da Silva CE, Hope AE, Ravanello MM, et al. (2005) Medical wastes management in the south of Brazil. Waste Management 25: 600-605.

Ferreira J, Bila DM, Ritter E, et al. (2012) Chemical healthcare waste management in small Brazilian municipalities. Waste Management \& Research 30: 1306-1311.

Govindan K, Kaliyan M, Kannan D, et al. (2014). Barriers analysis for green supply chain management implementation in Indian industries using 
analytic hierarchy process. International Journal of Production Economics 147: 555-568.

Gunasekaran A, Irani Z and Papadopoulos T (2014) Modelling and analysis of sustainable operations management: Certain investigations for research and applications. Journal of the Operational Research Society 65: 806-823.

Gupta S and Boojh R (2006) Report: Biomedical waste management practices at Balrampur Hospital, Lucknow, India. Waste Management \& Research 24: 584-591.

Hanumantha Rao P (2009). Hospital waste management system - A case study of a south Indian city. Waste Management \& Research 27: 313-321.

Harhay MO, Halpern SD, Harhay JS, et al. (2009) Health care waste management: A neglected and growing public health problem worldwide. Tropical Medicine \& International Health 14: 1414-1417.

Ho W (2008) Integrated analytic hierarchy process and its applications A literature review. European Journal of Operational Research 186: 211-228.

Insa E, Zamorano M and López R (2010) Critical review of medical waste legislation in Spain. Resources, Conservation and Recycling 54: 1048-1059.

Ishizaka A and Labib A (2011) Review of the main developments in the analytic hierarchy process. Expert Systems with Applications 38: 14336-14345.

Karamouz M, Zahraie B, Kerachian R, et al. (2007) Developing a master plan for hospital solid waste management: A case study. Waste Management 27: 626-638.

Marinković N, Vitale K, Holcer NJ, et al. (2008) Management of hazardous medical waste in Croatia. Waste Management 28: 1049-1056.

Moreira MM and Günther WMR (2013) Assessment of medical waste management at a primary health-care center in São Paulo, Brazil. Waste Management 33: 162-7.

Nagesha N and Balachandra P (2006) Barriers to energy efficiency in small industry clusters: Multi-criteria-based prioritization using the analytic hierarchy process. Energy 31: 1633-1647.

Oroei M, Momeni M, Palenik CJ, et al. (2014). A qualitative study of the causes of improper segregation of infectious waste at Nemazee Hospital, Shiraz, Iran. Journal of Infection and Public Health 7: 192-198.

Rutala WA and Mayhall CG (1992). Medical waste. Infection Control \& Hospital Epidemiology 13: 38-48.
Saaty TL (1990) How to make a decision: The analytic hierarchy process. European Journal of Operational Research 48: 9-26.

Sarker MAB, Harun-Or-Rashid, Hirosawa T, et al. (2014) Evaluation of knowledge, practices, and possible barriers among healthcare providers regarding medical waste management in Dhaka, Bangladesh. Medical Science Monitor: International Medical Journal of Experimental and Clinical Research 20: 2590-2597.

Shi H, Peng SZ, Liu Y, et al. 2008. Barriers to the implementation of cleaner production in Chinese SMEs: Government, industry and expert stakeholders' perspectives. Journal of Cleaner Production 16: 842-852.

Sipahi S and Timor M (2010) The analytic hierarchy process and analytic network process: An overview of applications. Management Decision 48: 775-808.

Townend B and Vallini G (2008) Healthcare waste management - The global paradox. Waste Management \& Research 26: 215-216.

Tsakona M, Anagnostopoulou E and Gidarakos E (2007) Hospital waste management and toxicity evaluation: A case study. Waste Management 27: 912-920.

Tudor TL, Barr SW and Gilg AW (2007) Linking intended behaviour and actions: A case study of healthcare waste management in the Cornwall NHS. Resources Conservation and Recycling 51: 1-23.

Vaidya OS and Kumar S (2006) Analytic hierarchy process: An overview of applications. European Journal of Operational Research 169: 1-29.

Vanany I (2011) An AHP based method to prioritize the barriers and critical success factors of RFID adoption in healthcare. International Business Management 5: 427-435.

Voss C, Tsikriktsis N and Frohlich M (2002) Case research in operations management. International Journal of Operations \& Production Management 22: 195-219.

Wilson DC, Rodic L, Scheinberg A, et al. (2012) Comparative analysis of solid waste management in 20 cities. Waste Management \& Research 30: $237-254$.

Windfeld ES and Brooks MS-L (2015) Medical waste management: A review. Journal of Environmental Management 163: 98-108.

Woolridge A, Morrissey A and Phillips PS (2005) The development of strategic and tactical tools, using systems analysis, for waste management in large complex organisations: A case study in UK healthcare waste. Resources Conservation and Recycling 44: 115-137. 